\title{
LA REVOLUCIÓN DE LOS PÍXELES ARTE Y VIDEOJUEGOS EN UN MUNDO DIGITAL
}

\author{
THE PIXEL REVOLUTION \\ ART AND VIDEO GAMES IN A DIGITAL WORLD
}

\author{
Agnés Garcia Oltra \\ (Universitat de València, España) \\ nessgar93@gmail.com
}

Recibido: 15 febrero 2020 Aceptado: 07 marzo 2020

\begin{abstract}
Resumen: La intervención y la importancia del arte en los videojuegos ha sido (y es) una revolución artística en la actualidad. Hemos pasado de la interacción a la acción ilustrativa de los escenarios y personajes, del píxel al vector o viceversa, llegando a la creación mediante la herramienta digital que ha supuesto una gran rebelión en todas las palabras en el arte y asimismo en la Historia del Arte. Por lo tanto, el presente estudio pretende acercar de forma breve y concisa el arte digital actual utilizado en los videojuegos como nuevas producciones artísticas.
\end{abstract}

Palabras clave: Videojuego; Arte Conceptual; Pintura Digital; Ilustración; The Legend of Zelda

\begin{abstract}
Nowadays, the intervention and importance of art in videogames has been (and is) an artistic revolution. We have moved from the interaction to the illustrative action of the scenes and characters, from the pixel to the vector or vice versa, arriving to the creation through the digital tool that has been a great rebellion in all the words in art and also in the History of Art. Therefore, the present study aims to bring the current digital art used in videogames as new artistic productions in a brief and concise manner.
\end{abstract}

Keywords: Videogames; Concept Art; Digital Painting; Pixel; Illustration; The Legend of Zelda

\section{INTRODUCCIÓN (Tutorial)}

El imaginario visual actual se caracteriza por ser interactivo donde las imágenes nacen, se desarrollan y tienen el peligro de desaparecer. Un ciclo vital inmaterial y en ocasiones 
efímero ocasionado por su soporte, la pantalla. El papel de las imágenes, cuya percepción es diversa y subjetiva, resulta ser un factor importante en la constitución de los videojuegos. Si bien, Israel Márquez, nos decía que desde el inicio, los videojuegos remitían a la televisión y al cine por la pantalla (Márquez, 2007, p.12), también lo hace, en cuanto a la interacción con esta. De la gran pantalla del cine recopilará toda esa escenografía e involucración del espectador y de la pequeña pantalla, con la aparición del control remoto, recogerá la interacción con las imágenes. Con toda seguridad, como bien nos decía Llorca Diez, la pantalla será el espejo tecnológico de la sociedad que entiende y representa la realidad conformando una experiencia visual fundamental (Llorca Diez, 2009, p.20).

Entre los píxeles reproducidos a través de la pantalla, se deja entrever de forma breve y concisa una evolución clara que configura una historia de los videojuegos en continua formación. A pesar de su origen militar, cabe empezar a introducir el mundo de los videojuegos ya como tal, nombrando el primer juego. Puesto que es difícil saber a ciencia cierta cuál fue el primero, Simone Belli y Cristian López Raventós, señalan el primer videojuego Nought and Crosses de Alexander S. Douglas de 1952. Como bien nos dicen se trata de "una versión computarizada del tres en raya ejecutada por un EDSAC (ordenador de la época) y permitía enfrentar un jugador humano contra la máquina" (Belli; López Raventós, 2008, p.162). Este hito, junto a dos juegos sucesivos como el tenis de mesa (Tennis for Two) o el Space War a lo largo de la década de los 60, provocó sin duda el desarrollo de las máquinas recreativas. Poco después, esa popularidad en la nueva industria, se tradujo a un campo más privado. Fue así como se impulsó hacia las máquinas domésticas (conocidas como videoconsolas) hasta finalmente llegar en paralelo a las consolas portátiles.

La evolución de las máquinas recreativas tanto domésticas como finalmente portátiles también, hizo así mismo un desarrollo estético, visual, musical e incluso de jugabilidad e interacción a su vez. De los gráficos vectoriales de Space War, pasando a las generaciones de los 8,16 e 32 bits 1 de las décadas de los 80 y 90 -las cuales marcan

\footnotetext{
1 Bit o en plural Bits, es un dígito del sistema de numeración binario, utilizado principalmente en ordenadores, se manifiestan de forma visual mediante las pantallas formando imágenes en base a retículas de colores llamados píxels.
} 
una evolución visual rápida y comprimida - llegarán a la pre-renderización2 para alcanzar el 3D. No obstante, será a partir del 2000 hasta la actualidad, donde el dominio visual y la calidad proporcionada por las nuevas máquinas y pantallas, dominarán la renderización, el 3D y el intento de llegar a una realidad virtual mediante el fotorrealismo3.

Los videojuegos a lo largo de la historia se han ido renovando de forma continua. Como hemos visto, acaban definiéndose por sus características comunes otorgando la posibilidad de clasificarse por categorías (Llorca Diez, 2009, p.33). Así pues, dentro de su consumo en el entretenimiento los encontraremos clasificados por árcade, plataforma, aventura o acción, entre una gran variedad. Esta gran variedad abre una ventana al elemento socializador, de ocio y aprendizaje de las TIC hacia los niños y jóvenes (Belli; López Raventós, 2008, p.160). De este mismo modo, también abre una vertiente hacia una nueva forma de expresión artística que se ha ido comprendiendo y desarrollando a lo largo de la historia de los videojuegos, pero que en la actualidad se ha ido haciendo notoria con la involucración de artistas en este campo.

En la vertiente artística de los videojuegos, Simone Belli y Cristian López Raventós señalan que la sociedad "parece casi incapaz de darle un significado, como en el arte contemporáneo, que a su vez no encuentra en la crítica tradicional la herramienta para analizar y estructurar una opinión, simplemente se limitan a describir como está compuesta la obra" (Belli; López Raventós, 2008, p.161). Sin lugar a dudas, a partir de la última década del siglo XX la estimación por el aspecto gráfico gana más importancia. No obstante, cabe poner un enciso, los videojuegos son un conjunto de diversas «artes» y no solo visual. Aun así, este artículo se centrará en los videojuegos como un producto posmoderno, donde la imagen es la protagonista y por eso, pondremos la atención en la vertiente artística, visual y como llega a su arte final. La metodología que se utilizará será un análisis crítico histórico-artístico, con la implicación de los estudios visuales para poder poner una valoración en el Game Art. Del mismo modo, ensalzar ese valor del arte

\footnotetext{
2 «Renderizar», «Renderización» 0 «Renderizado» es el castellanismo del verbo inglés «Render», no hay traducción al castellano, y se suele emplear para la acción de crear y modelar imágenes por ordenador. Véase en: https://www.fundeu.es/consulta/renderizar-3/ (Consultado el 15/02/2020)

3 «Fotorrealismo» es la cualidad de una imagen generada y modelada por un ordenador mediante la renderización, que intenta imitar a la fotografía.
} 
en los videojuegos mediante un análisis del arte inicial y final proporcionado por el llamado Concept Art en el caso del videojuego The Legend of Zelda Skyword Sword.

\section{Nivel 1. GAME ART. VIDEOJUEGOS, INSPIRACION Y CREACION DE ARTE}

El potencial artístico de los videojuegos se configura como nuevos medios de producción de arte. Como bien decía Grant Tavinor, muchos adquieren ahora la importancia envolvente de imágenes gráficas y auditivas impresionantes. Aun así, ese potencial sigue la nueva cultura nacida a través de ellos, donde se desarrolla un espacio de memoria viva cuyo resultado procede de la experiencia de las emociones (Tavinor, 2009, p.1). Esas experiencias -que las adquiere el jugador-no solo hacen más que expandir el juego hacia nuevos horizontes en el arte y su potencial digital. Porqué los juegos son un material para expresar la percepción del jugador mediante la «performance» que es el propio juego (Sharp, 2015, p. 107).

Los videojuegos comparten no solo cualidades artísticas sino formas culturales en su medio visual y en su narrativa. John Sharp nos decía que "games are not always approached as a cultural form unto itself, but instead as a cultural phenomenon that can be used, like any others aspect of culture, to inform, inspire, or create art" (Sharp, 2015, p.19). Es decir, los videojuegos aparte de poder ser una forma cultural en sí misma, también pueden ser fuentes derivadas para la creación de arte. Clarke y Mitchell en su obra Art and Videogames del 2007, nos conducen hacia ese mismo camino cuando nos introducían el «Game Art» como una vertiente que no se centraba solo en su medio, en su lenguaje de programación o en la estética, sino que también proporcionaban una inspiración y creación de un arte derivado. Muchos son los juegos icónicos apropiados para crear arte en sí, Clarke y Mitchell llaman a este tipo de fenómeno como una «iconografía de los videojuegos» que es utilizada en otros medios (Clarke; Mitchell, 2007, p.10). Un fenómeno que ya sucedió en el arte durante el Pop Art siguiendo los pasos de Andy Warhol (Pittsburgh, 1928-1987, Nueva York) y artistas de las vanguardias, con la apropiación de elementos de la cultura popular para la realización de la obra. Aun así, no solo existen artistas que desarrollan esta iconografía de la apropiación, sino la reproducción de escenografías y personajes de los videojuegos por medio de otras artes, como el llamado «digital painting», es decir, la "pintura" digital. Por lo tanto, podemos 
considerar el Game Art como bien nos decía Lara Sánchez como un subgénero del New Media Art "que trabaja en torno a los videojuegos para luego extender nuestra mirada hacia autores y movimientos de vanguardia que trabajaron de algún modo sobre lo lúdico o el juego en relación al arte como factor de alteración del orden predominante" (Sánchez, 2012, p.37).

El Game Art, no solo será el medio de inspiración y creación para artistas en base a los videojuegos, sino que configurará un estilo gráfico icónico identificable (Clarke; Mitchell, 2007, p.11). Por lo tanto, existe una estética en los propios videojuegos que hace que puedan ser ellos mismos una creación artística. Existe un debate en torno a si los videojuegos comerciales son o no arte, tal vez más allá de la experiencia estética que pueda haber, existen otros factores que intervenir dentro del debate, pues no todos los videojuegos que se comercian pueden ser llamados obras de arte. No obstante, fuera de este debate - pues se centraría en el concepto ambiguo de que es realmente «arte»- nos centramos en la base estética y gráfica de los videojuegos.

Encontramos en la actualidad grandes proyectos comerciales que son verdaderas obras de arte como Okami (2006), The Last of Us (2013), The Legend of Zelda Skyward Sword (2011) este último, en cuyo caso, gráficamente se ha visto superado en la saga por The Legend of Zelda Breath of Wild (2017). Algunos de estos ejemplos, tienen como base, fuertes industrias que han ido creciendo y siguiendo el ritmo tecnológico, que da como resultado, una realidad virtual encaminada hacia el fotorrealismo gráfico y animado. No obstante, esto da a que las franquicias se centren más en estos avances y no tanto en la necesidad de innovar (como sucede con la saga de videojuegos Pokémon [1]) (Clarke; Mitchell, 2007, p.15). La saga Pokémon dedicada a las consolas portátiles y recientemente introducida en los Smarthphones es el mejor ejemplo. Con la llegada de la realidad aumentada se ha intentado introducir, dejando de lado la vertiente gráfica, los dispositivos inteligentes. Pokémon Go (2016) es tan solo el inicio tecnológico, que acabará sobrepasando al hiperrealismo gráfico y llegando a la realidad virtual mediante la realidad aumentada. Combinando así las mejoras gráficas visuales con las nuevas tecnologías de realidad virtual. 

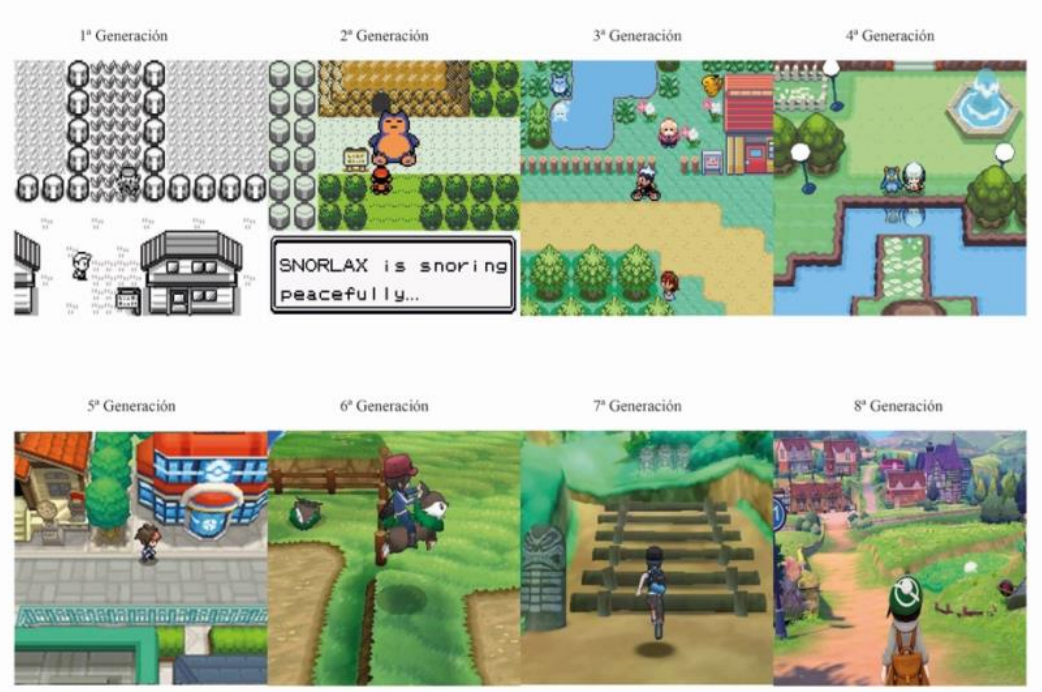

1. Fotogramas por generaciones de los videojuegos de Pokémon.

Por otra parte, también tenemos en la industria del videojuego el arte independiente, mediante los juegos «indie». Estos videojuegos se difieren de los convencionales (Clarke; Mitchell, 2007, p.15) porque sus objetivos son totalmente distintos. Gris (2018) del estudio independiente Nomada Estudio, regala una experiencia única al jugador. La visualidad gráfico-artística, no pasa desapercibida, gracias a la colaboración de diversos artistas, destacando al artista catalán Conrad Roset, que es además el director creativo del juego. Por consiguiente, tanto los comerciales como los independientes, estan ante la distinción de «Game Art» y «Art Game», dos conceptos clave para entender como uno se considera arte y el otro tan solo partícipe de la cultura de ocio. El Game Art se podrá exhibir en una galería de arte y el Art Game será con destino comercial, pero tanto lo uno, como lo otro, pueden tener una finalidad de creación artística y no haber una distinción entre ellos. A pesar de eso, Clarke y Mitchell proponen Art Game como género en base a los juegos independientes para una clara distinción con los Game Art (Clarke; Mitchell, 2007, p.15).

Tal vez, esta distinción difusa no difiera del fenómeno arte en los videojuegos, sino que más bien se potencie, no como un movimiento artístico, ni género, sino más bien como un recurso artístico. Sharp nos recordaba que el arte conceptual ya abrió la posibilidad de la práctica artística a cualquier cosa, y no solo por su forma de cuestionar el arte y su funcionamiento interno, sino que un videojuego será arte si tiene un fin 
artístico que el propio creador o creadores deseen (Sharp, 2015, p.21). Por lo tanto, los videojuegos es un espacio de posibilidades para abordar con sensibilidad artística, es un medio más allá del entretenimiento, es un sustrato creativo como las películas, la pintura o la escultura (Sharp, 2015 p.106). La importancia de la recreación gráfica recaerá por tanto en la narrativa, en la localización y en la cronología, es decir, espacio, tiempo y sucesión de eventos. Provocando al espectador una mirada de forma subjetiva al juego y su participación mediante la experiencia emocional y sensorial.

\section{Nivel 2. CONCEPT ART. EL PRINCIPIO Y EL FINAL DEL PASO DE VIDEOJUEGO A OBRA DE ARTE}

Si bien el Art Game y el Game Art constituyen al fin y al cabo dos conceptos que involucran los videojuegos con el arte, la creación de este mismo llega a ser un proceso laboriosamente artístico. El conocido «Concept Art»o «Arte Conceptual» es tal vez la primera parte para su realización en los planos estéticos y visuales. Pero también es la última, puesto que en muchos casos se acaban utilizando en la promoción de lanzamiento del mismo juego. Concept Art es un proceso de preproducción, que no solo lo utilizan los videojuegos sino también en los campos de la animación y el cine. Lara Sánchez en su tesis realizada en 2012 Arte y Videojuegos: Mecánicas, estéticas y diseño de juegos en prácticas de creación contemporánea, nos describe terminológicamente el Concept Art como (Sánchez, 2012, p.355):

\footnotetext{
"El concept art son las ilustraciones mediante las cuales se define la presentación visual de un diseño, una idea, una escena o un estado de ánimo antes de su representación final en películas, videojuegos, trabajos de animación, comics, escenografía, diseños de moda, diseños arquitectónicos, etc."
}

De cierto modo es el punto de partida de cualquier videojuego - sin dejar de lado la participación de las otras disciplinas en él y centrándonos solo en la vertiente visualdonde se forjan las ideas principales en cuanto a constitución de escenografías, personajes u objetos. Estos, por consiguiente, son trabajados por un equipo de artistas especialistas, donde la documentación y el trabajo en equipo será esencial para que esas primeras ideas conceptuales progresen. Además, añadiendo el papel de las técnicas de producción, que 
han ido de la mano en la evolución tecnológica, tenemos desde el boceto previo en lápiz hasta el uso de softwares específicos como son Adobe Photoshop o Adobe Illustrator.

Uno de los casos más llamativos de la última década, ha sido un videojuego que no solo se ha inspirado en el arte, sino que es arte en sí mismo -desde la puesta de nuevos modos de jugabilidad en la misma saga, pasando por la historia, hasta la Banda Sonora o la producción visual- es el The Legend of Zelda Skyward Sword del 2011. Este juego producido para la consola Wii de Nintendo, involucra al jugador mediante la interactividad que proporciona el Wii MotionPlus (una extensión del control remoto o mando de la Wii que permite al jugador hacer movimientos más complejos con precisión). Esta expansión permite (a diferencia de otros juegos de la saga The Legend of Zelda) el poder manejar objetos, herramientas o armas ellos mismos, como la espada.

Por otra parte, a nivel visual y gráfico se ve caracterizado no solo por el afán de llegar hacia el fotorrealismo característico de los gráficos por ordenador ni por el «CelShading»4 como tal, que ya se había utilizado en otros juegos anteriores. Esta vez, la estética visual, se enmarcaba por la mezcla de ambos con el objetivo artístico de llegar a convertir el juego en un lienzo de inspiración impresionista y postimpresionista con un estilo en acuarela. Esto se debe en primer lugar por la incorporación del Wii MotionPlus, para que se viese claramente el manejo interactivo con los objetos del juego. Y en segundo lugar por la narrativa de la historia.

The Legend of Zelda cumple las características del género de los cuentos de hadas. Si recordamos que el cuento de hadas a nivel estructural "funciona gracias a la oposición y contraste de conceptos básicos que se definen mutuamente y que ofrecen al niño un entendimiento adecuado del mundo que lo rodea" (Castellanos Vàzquez, 2016, p.259). Es decir, mediante las relaciones semióticas de bueno/malo o día/noche, la composición visual de dibujo y colores recrearían en si ese género literario transformado en una experiencia multimedia. No obstante, Skyward Sword se separa del resto de la saga por

\footnotetext{
4 El Cel-Shading es una técnica para la realización de "modelación en tres dimensiones no foto-realista que tiene como finalidad el hacer que las imágenes generadas con modelos 3D al ordenador parezcan imágenes dibujadas a mano con bordes espesos y evidentes colores simples". Véase en: https://juegosadn.eleconomista.es/articulo-explicando-conceptos-el-cell-shading-ar-14/ (Consultado el $13 / 02 / 2020)$
} 
ser el comienzo de la leyenda, y por lo tanto sería un cuento de hadas dentro del propio universo Zelda.

Es por eso, el trabajo realizado desde el inicio con el Concept Art, vemos no solo esas primeras ideas de constituir un comienzo de una historia dentro de un universo ya creado (manteniendo los personajes principales del héroe Link y la princesa Zelda), sino que además, ya componen esos trazos de dibujo y ese color vivo de una acuarela [2]. Además, los propios personajes diseñados desde una perspectiva medieval y de fantasía aluden al cuento de hadas ya de por si, por la configuración de sus características, que ya venían de serie desde el primer videojuego de la saga. Es decir, orejas puntiagudas, colores llamativos en los peinados, etc. Eso se le suma además de la conformación de una propia mitología dentro del juego, personajes de leyenda que se repiten y no solo Link o Zelda, sino por ejemplo Impa, protector de Zelda [3]. El Concept Art del diseño de personajes es muy complejo dentro del universo Zelda, los personajes son característicos por tener su propia personalidad, su historia y por lo tanto un papel dentro del desarrollo narrativo del juego. Uno de los ejemplos más llamativos que podemos ver recopilado en el libro de Hyrule Historia es el diseño de personajes para la tienda de pociones. Hasta 10 personajes distintos diseñados nos aparecen en este recopilatorio, todos ellos distintos y con su propia personalidad [4].

Como vemos, el diseño de personajes sigue el mismo camino que el resto de la saga. Por lo contrario, el diseño de escenarios se desvincula en parte de donde normalmente se desarrolla la historia, Hyrule. En este videojuego nos encontramos dos escenarios, el cielo donde tenemos Celestea, sus habitantes y la tierra flotante llamada Altárea y el mundo inferior. Este último, está compuesto principalmente por el Bosque de Farone, el Volcan de Eldin y el Desierto de Lanayru. Celestea estará diseñada como un lugar de paz, donde los habitantes viven harmónicamente en Altárea obviando el mundo inferior. Por otro lado, ese mundo inferior reinará por elementos distintos, entre ellos destacar los extraños habitantes que conviven con el dominio del poder maligno, y por ende la aparición de personajes y elementos malvados. Para ello se utilizará un diseño semiótico del cuento de hadas, lo feo y lo malo se representa mediante escenarios con colores intensos, mazmorras oscuras y laberínticas [Fig.5]. Cada uno de esos lugares tendrá la representación de los elementos de la naturaleza: agua, fuego y tierra -pues el 
viento estará representado por Celestea- además constarán con diseños de distintos templos y dentro de ellos mazmorras con puzles que hay que pasar y derrotar (un sistema de juego que lleva The Legend of Zelda desde su creación). Asimismo, hay que añadir que esa representación de los elementos proviene de toda esa tradición filosófica budista arraigada también en Japón y de la importancia que se le da a la naturaleza en si, manifestada a través del juego y su planteamiento.

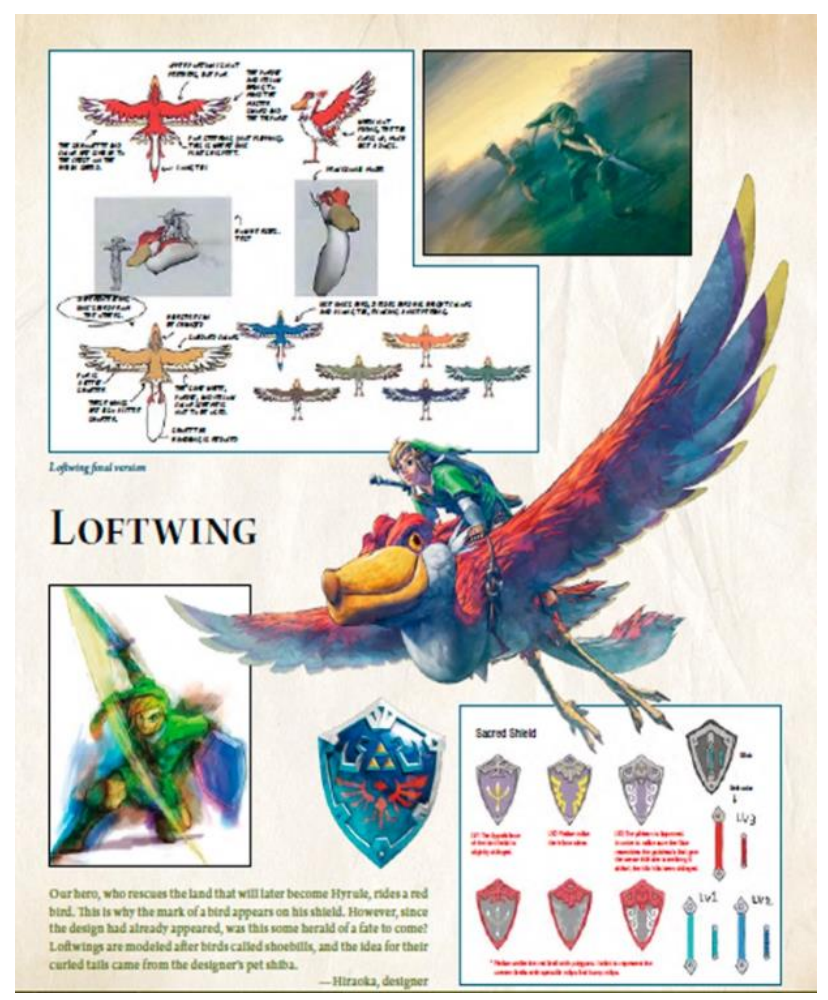

2. Diseño del Pelícaro y del escudo sagrado. Imagen extraída de: HIMEKAWA, Akira; MIYAMOTO, Shigeru; AONUMA, Eiji (2011), The Legend of Zelda. Hyrule Historia, Dark Horse Comics, Milwaukie, p.9. 


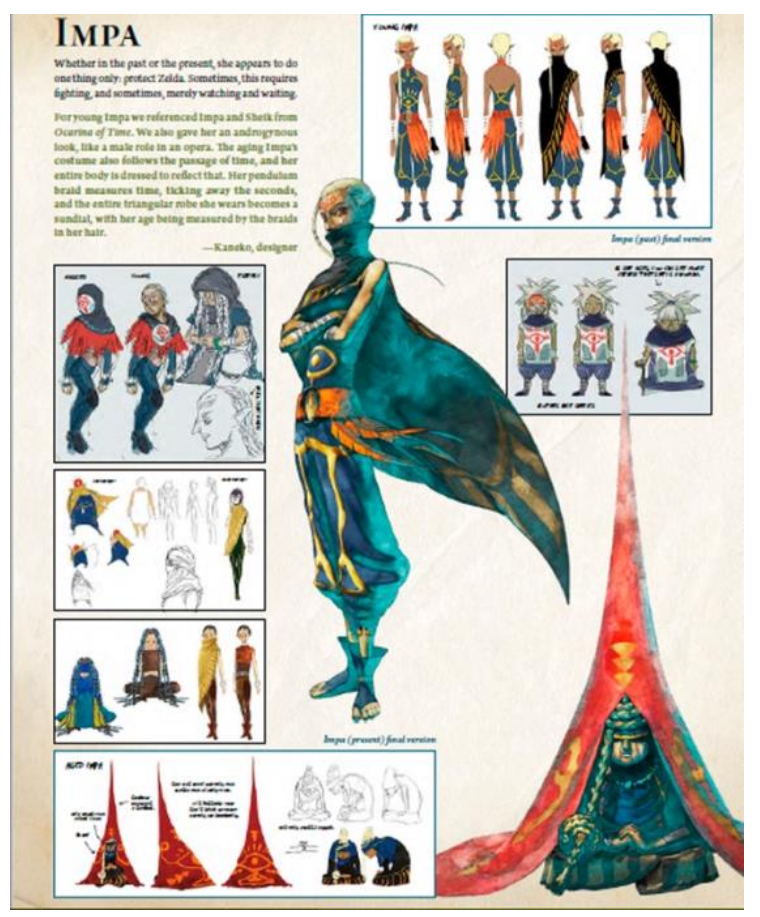

3. Diseño del personaje Impa. Imagen extraída de: HIMEKAWA, Akira; MIYAMOTO, Shigeru; AONUMA, Eiji (2011), The Legend of Zelda. Hyrule Historia, Dark Horse Comics, Milwaukie, p.16.

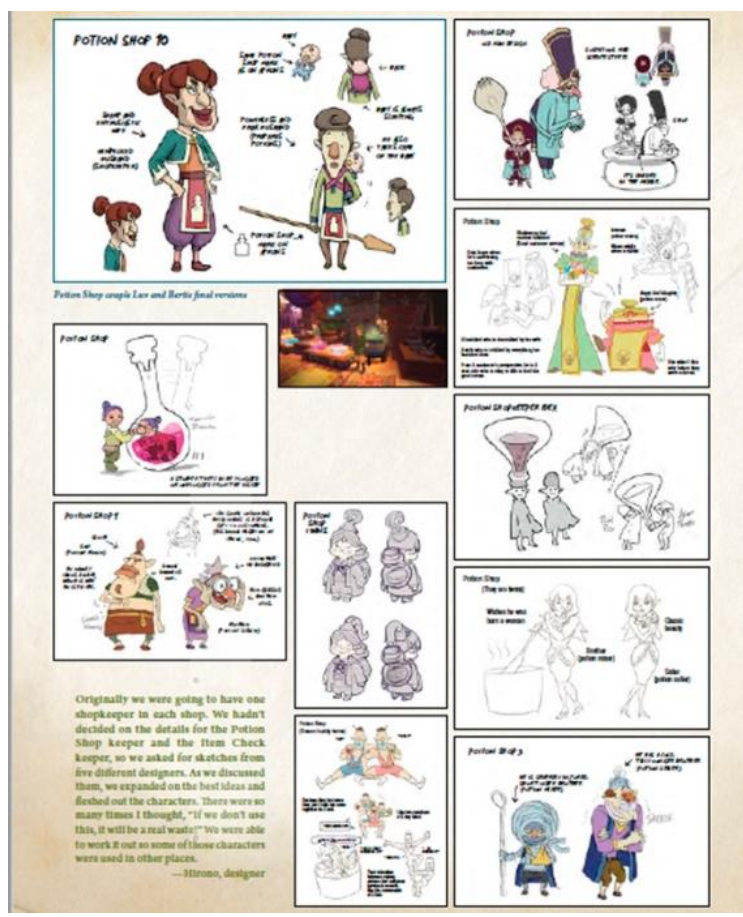

4. Diseño de personajes para la Tienda de Pociones. Imagen extraída de: HIMEKAWA, Akira; MIYAMOTO, Shigeru; AONUMA, Eiji (2011), The Legend of Zelda. Hyrule Historia, Dark Horse Comics, Milwaukie, p.28. 


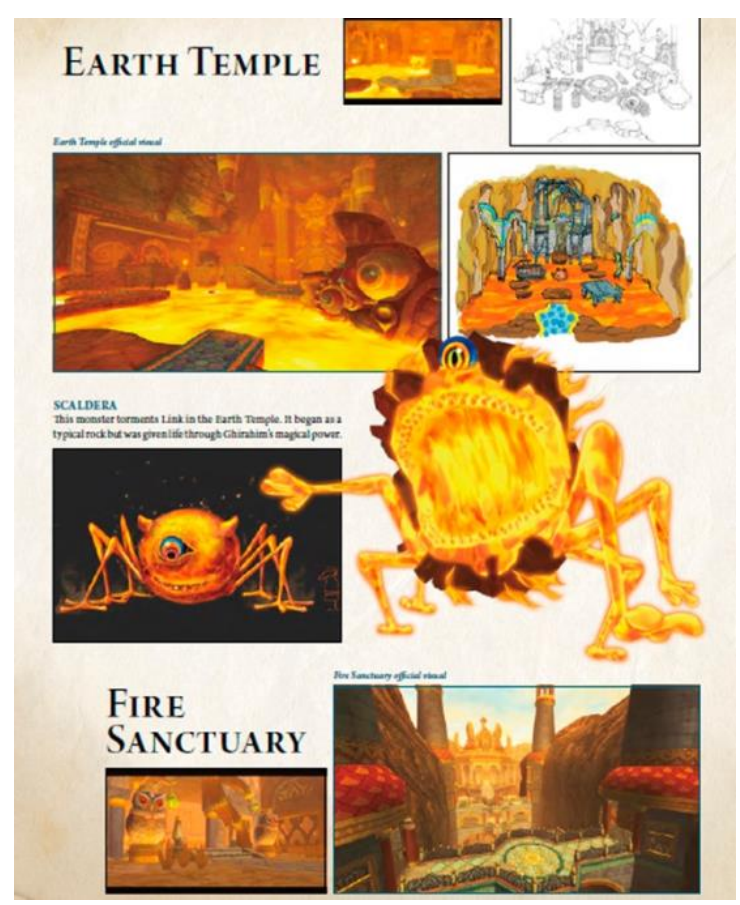

5. Diseño de escenografía. Imagen extraída de: HIMEKAWA, Akira; MIYAMOTO, Shigeru; AONUMA, Eiji (2011), The Legend of Zelda. Hyrule Historia, Dark Horse Comics, Milwaukie, p.50.

Otro diseño escenográfico que interviene como intermediario entre el cielo y la tierra inferior, entre el bien y el mal, será la Tierra del Presidio, donde se encuentra el Templo del Presidio. Muy característico por las alusiones a otros templos de la saga como el Templo del Tiempo que nos podemos encontrar en Ocarina of Time donde además siempre se encuentra la espada maestra. Añadir también el encuentro de una decoración de emblemas ya vistos a lo largo de la saga de Zelda.

Sin lugar a dudas, el Concept Art, de Skyword Sword presenta una preproducción artística muy compleja, que no deja en vano un proyecto único que llegó a ser contemplada como una obra de arte dentro del mundo de los videojuegos. De igual manera, el uso del Concept Art no solo fue un inicio para el juego, con el que celebrarían el 25 aniversario, sino también se utilizó para el lanzamiento de este. Encontramos, por tanto, diseños finales del Concept Art utilizados como presentación visual del propio videojuego y por lo tanto es un proceso necesario y notorio del inicio hasta el final, que comprende el videojuego para que pueda llegar a ser una potencial obra de arte. Considerando así, su valoración de principio a fin como parte del Game Art. 


\section{The Final Boss. CONCLUSIONES}

Los videojuegos forman parte de la cultura visual actual, se han introducido en nuestro día a día, dentro también de la sociedad, del entretenimiento, del ocio gracias a la pantalla. La velocidad que ha ido cambiando la tecnología tanto las máquinas recreativas y las pantallas han dado lugar a que no solo los videojuegos sean un entretenimiento vacío, sino que llega a ser un potencial artístico. Por eso mismo, no son solo parte de la cultura, sino que son cultura en sí mismos.

Son parte del Game Art inspirador tanto en el New Media Art hasta las manifestaciones más actuales donde se realizan ilustraciones y dibujos, mediante softwares digitales. Además de formar parte de la configuración de un estilo gráfico icónico, que se identifica y crea una estética, que pone al debate la creación artística no solo de la inspiración creativa sino del propio arte en el videojuego. Sin lugar a dudas es un lienzo multimedia donde poder plasmar una experiencia emotiva y sensorial para que el espectador sea partícipe.

Por lo tanto, la elaboración de este es necesaria, no solo por la involucración de un equipo multidisciplinar con la colaboración de artistas trabajando en el campo, sino que, desde la idea inicial, el punto de partida de la configuración de un videojuego debe de pensarse como arte y diseñarse con detalles. El ejemplo de The Legend of Zelda Skyward Sword ha sido pensando desde sus diseños iniciales y siguiendo una narrativa del universo Zelda, como algo único, inimitable, es decir como una obra de arte, que sin duda ha marcado la celebración del 25 aniversario de la saga de videojuegos, pero que incluso se ha visto superado por el fotorrealismo y el cambio de jugabilidad con la llegada posterior de The Legend of Zelda Breath of Wild en 2017.

En conclusión, no solo estamos ante una evolución constante tecnología del entretenimiento (como son las videoconsolas), sino que el producto de ocio (los juegos) están en constante renovación. Una renovación que contempla nuevas formas de contar historias mediante la jugabilidad, nuevos modos de interrelación juego-jugador, nuevas bandas sonoras icónicas, sino también poniendo el énfasis en la superación gráfica que se 
ha ido adaptando a la revolución visual conformando de nuevo parte de la cultura visual actual.

Por lo que, en definitiva, los videojuegos se pueden incluir dentro de los parámetros artísticos de la Historia del Arte como una revolución artística que abarca mucho más que la estética visual y gráfica, sino que es un cúmulo de artes dentro de un mismo medio, que en cuyo caso, lo convierte en una auténtica revolución dentro del arte.

\section{REFERENCIAS BIBLIOGRÁFICAS}

Belli, Simone; López Raventós, C. (2008), Breve Historia de los videojuegos. Athenea Digital, $\mathrm{n}^{\circ} 14$, pp. 159-179.

Castellanos Vázquez, T. A. (2016). El cuento de hadas en los nuevos medios: ¿Cómo participa la hipertextualidad en el desarrollo del infante? Caso de estudo The Legend of Zelda. Razón y Palabra, vol.20, nº4, pp. 257-286.

Clarke, Andy; Mitchel, Grethe (2007). Videogames and Art. Intellect Books: Bristol.

Egulia Gómez, J.L; Contreras Espinosa, R; Solano Albajes, L. (2013), Videojuegos: Conceptos, Historia y su potencial como herramientas para la educación. 3cTIC: Cuadernos de desarrollo aplicados a las TIC, vol. 2, n², pp. 1-14.

Himekawa, Akira; Miyamoto, Shigeru; AONUMA, Eiji (2011), The Legend of Zelda. Hyrule Historia. Dark Horse Comics: Milwaukie.

Llorca Diez, María de los Ángeles (2009). Hábitos y uso de los videojuegos en la comunicación visual: Influencia en la inteligencia espacial y el rendimiento escolar. Universidad de Granada: Granada.

Sánchez Coterón, Lara (2012). Arte y Videojuegos. Mecánicas, estéticas y diseño de juegos en prácticas de creación contemporánea. Universidad Complutense de Madrid: Madrid.

Sharp, John (2015). Works of Games: On the Aesthetics of Games and Art. MIT Press: Cambridge.

Tavinor, Grant (2009). The Art of Videogames, John Wiley \& Sons Incorprated: United Kingdom. 
Anónimo (2011). Explicando conceptos: el Cell Shading. Reportaje. Recuperado de: https://juegosadn.eleconomista.es/articulo-explicando-conceptos-el-cell-shading-ar-14/ Anónimo (2011). Zelda: Skywars Sword, el impresionista origen de la Espada Maestra. Recuperado de: https://www.europapress.es/portaltic/videojuegos/noticia-zeldaskyward-sword-impresionista-origen-espada-maestra-20111103141657.html 